\title{
Leaving Our Comfort Zone
}

\author{
ANDREW CRUSE \\ The Ohio State University
}

Explicitly addressing the construction of comfort provides a vital pedagogical approach to understanding and designing with architecture's ecological entanglements. Such entanglements were historically discussed in fiction as part of a civilizing process. Today, the dominance of air conditioning, and its related comfort standard, have largely eliminated the conscious consideration of comfort from architectural education. Architects' collective difficulty in formulating imaginative design responses to climate change stems in part from our inexperience with alternative theories of comfort and diverse interior climates. This paper traces how the author has integrated a comfort-based approach to teaching in a history seminar, an options studio and a building systems class. This approach removes students and faculty from our comfort zone to offer a new framework for design.

\section{I.}

As a discipline, architecture became ecological through parables and myths recounting the construction of a primitive hut. Depending on the story, the hut's hearth, walls, entablature, or some other architectural element, marked it as separate from what existed before, from what was natural. In discussing such stories, Joseph Rykwert goes so far as to speculate on the existence of Adam's house in the Garden of Eden. ${ }^{1}$ Yet if we shift from art historical questions concerning the architectural artifact of the hut, to ecological questions about the architectural environments such huts created-in other words, the comforts they provided-our attention is drawn to another genre of story, one that began with Daniel Defoe's Robinson Crusoe (1719). ${ }^{2}$ Robinson Crusoe is not likely to appear on syllabi for architectural studio, history or technology classes. Yet Defoe's story was one of the first to make explicit the material, technological and psychological construction of comfort. It recounts nearly three decades of eponymous hero's life after a shipwreck left him stranded on a deserted island. The island's environment is the book's principal antagonist; and its main narrative revolves around Crusoe consciously creating his own comfort in response to the island's ecological conditions. Most simply, this involves Crusoe's moves from cave to tent to cottage and bower. Each architectural development is accompanied by related advances in his ergonomic, alimentary and psychological comforts (figure 1). At the beginning of the 18th century, when Robinson Crusoe was written, the construction of comfort was just becoming explicit in Western Europe and North America, largely driven by the refinement of sensibilities through the accumulation of consumer goods. ${ }^{3}$ The sociologist Norbert Elias described this as a "civilizing process," characterized by decreasing thresholds of tolerance for sensuous experiences such as temperature, smell and taste. ${ }^{4}$ Architectural comfort standards, first developed at the start of the 20th century, fit this pattern, as thermal comfort was restricted to a narrow band of temperature and humidity which could only be created using the new technology of air conditioning. This artificial weather transformed the variation of outdoor climate into a stable indoor climate, designed to satisfy these newly established standards. Today's dominant comfort model, the Predicted Mean Vote, holds that such comfort preferences remain constant across space and time, and do not vary with gender, age, social or environmental differences. ${ }^{5}$ Embodied in real estate guidelines and building codes, architectural education accepts this fixed idea of comfort as an objective truth.

Explicitly addressing the construction of comfort provides a vital pedagogical approach to understanding and designing with architecture's ecological entanglements by revealing the assumptions that undergird normative approaches to the interior climate of buildings. Global climate change is heightening our collective consciousness of comfort. Biologists, sociologists, historians and others in the sciences and humanities are working to recognize the role comfort in our evolution, our social history, and our public policy. ${ }^{6}$ As it becomes increasingly difficult to separate the static and controlled interior climates of buildings from unpredictable and extreme exterior climates, architects and architectural educators must also engage is this discussion. Comfort, like climate, is not a stable

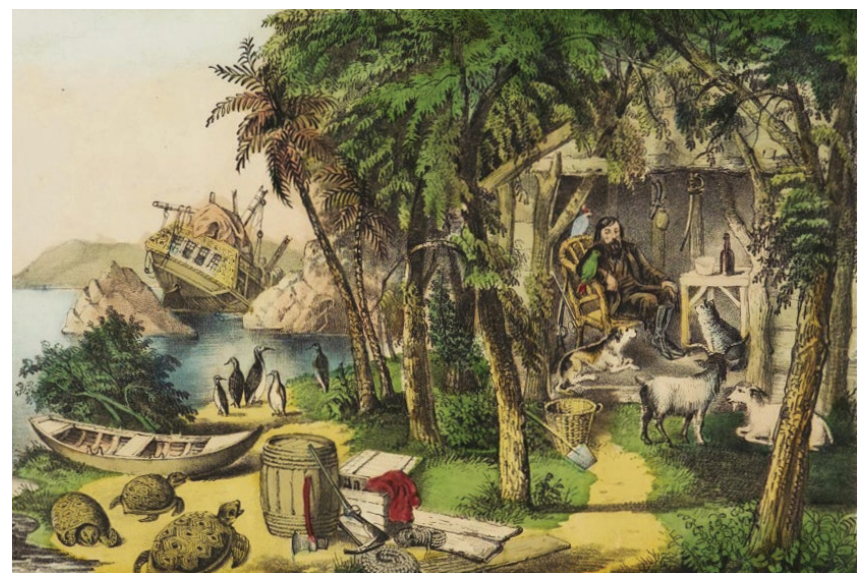

Figure 1. Robinson Crusoe and His Pets. Currier \& Ives, New York, 1874. 
index of energetic balance, but a condition of flux on which human activity has a direct impact. Buildings sit at the intersection of metabolism and meteorology, culture and climate. They are well positioned to practically and creatively respond to environmental changes. Proposing alternative notions of comfort is a way of disturbing certainties like the relationship of interior and exterior environments, of design and engineering, and of culture and energy. Explicitly addressing comfort removes us from our comfort zone and gives us the opportunity to find new types of comfort in the evolving context around us. In what follows, I want to outline how I have made the topic of comfort explicit in a history seminar, an options studio and a building systems class.

II.

My initial interest in architectural comfort was historical: I wanted to understand why today architects generally don't consider comfort during the design process. In over ten years of professional practice on a range of civic and commercial buildings, I don't recall any discussion of comfort more sophisticated than whether or not a building should have operable windows, or where to locate the thermostat. Comfort was most often directly addressed only in the Basis of Design document, which referred to the ASHRAE 55 comfort standard. How did something so fundamental to architecture as the interior environment nearly disappear from building design?

Existing architectural histories offered little help apart from a few exceptions such as Lisa Heschong's soft manifesto Thermal Delight in Architecture (1979). When architectural historians did consider the interior environment, they focused largely on the technology used to provide comfort, rather than the idea of comfort itself. Reyner Banham's The Architecture of the Well-Tempered Environment (1969, 2nd ed. 1984), is a prime example. Although the adjective "welltempered" figured prominently in the title, the book doesn't address what constituted comfort.

In the seminar "An Atlas of Novel Comforts" students examine the connections between different forms of comfort and different forms of architecture. When historians and critics consider what is essential to architecture, they typically focus on buildings' visual aspects such as form, space and materials. Comfort is not considered one of these essential qualities. The seminar reversed this hierarchy to study how ideas of comfort affected building form, space and materials.

The class follows a typical seminar structure: weekly readings were organized around themes, and we spend class time discussing these readings. The seminar begins by looking at three broad topics: historical shifts in sensual hierarchy, the development of climate observation and science, and the cultural construction of comfort. It then shifts to consider specific architectural examples that directly engage with the construction of comfort, including the development of the greenhouse, how hospitals and schools were affected by ideas of health and disease, and the design of solar houses. The last part of the seminar addresses the positive role played by discomfort, as comfort's complement rather than its opposite, through systems art and the architectural sublime.

Weekly readings, podcasts and videos are drawn from architectural and art history, as well as the history of medicine and science, anthropology and new journalism. Some are written in a staid academic style, while interviews, first person accounts and fictional narratives provide alternative forms of narrative better able to capture the experience of comfort. These more personal accounts often had a greater impact of the students' thinking and our collective discussions than more familiar forms.

At the start of the semester, each student identifies a research question they want to pursue related to the seminar's scope. I meet individually with students twice during the semester as they develop their projects, and they do a short, PechaKuchastyle presentation to the class at mid-semester. The final two classes are devoted to student presentations. In the past, one student looked at the history of swimming pools through the denaturing of the aquatic environment in competition pools, and a sanitizing of the sublime in recreational ones. Another looked at the history of sensory deprivation as both a restorative and punitive experience. She ended her presentation with the first person account of a visit to a sensory deprivation tank. A third student looked at the history of boardwalk funhouses, and connected some of their tricks to contemporary senior housing through the creation of environments that engaged kinesthetic experience.

This seminar opens a window on comfort as a vital yet understudied aspect of architecture's ecological history by providing a select history of architecture as environment-making. While architectural education often distinguishes between the rules-based learning of technology classes and the expectation of innovation in design studio, the subject of comfort helps students to bridge the gap between these two aspects of their education by understanding comfort as a condition that has evolved historically. The historical study of comfort moves students beyond the formal, art historical approach to architecture found in many history classes by bringing in a wide range of voices (scientists, journalists, fiction writers) and by addressing the experiential aspect of design. Students leave the seminar with an increased ability to distinguish and understand different architectural environments, and a desire to apply what they have learned to their own design work.

III.

While a history seminar is good format to explore alternative ideas about comfort through reading and research, I wanted to see how such ideas could form the basis for a design studio, the core of an architectural education. In the spring of 2018, I taught a vertical options studio (for junior 


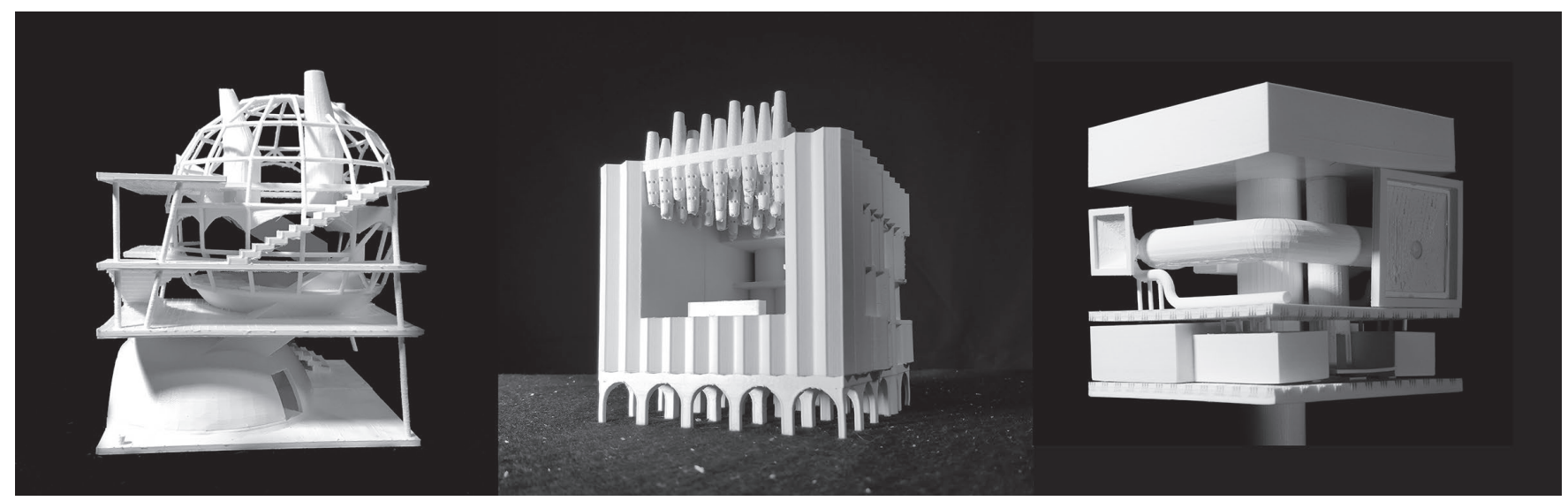

Figure 2. Curating Comforts Student Models, from L to R Guanming Huang, Rachel Hill and Mason Johnson.

and senior undergraduates) called "Some Like it Hot" to design a new athletic club. Similar to how Rem Koolhaas in Delirious New York (1978) looked to the existing Downtown Athletic Club as a model for a programmatically-driven metropolitan architecture, we looked at the Athletic Club of Columbus to provide a model of comfort-driven, climatic architecture. This desire was guided by a seldom noted paradox of architectural modernism: while new material technologies visually connected indoor and outdoor spaces, contemporary environmental technologies thermally separated indoor and outdoor climates. This pattern of visual connection and thermal separation continues today as heterogeneous building forms contain largely homogeneous interior environments. The proposition of this studio was that architects' collective difficulty in formulating imaginative design responses to climate change stems in part from our inexperience with diverse interior climates, and alternative theories of comfort.

The studio began with an exercise to introduce the students to designing with comfort using readymade comfortfocused spaces. Drawn from a list of examples, these ranged from the small scale such as the four-poster bed, spray booth and conversation pit, up to larger spaces such as the hammam, aquarium and wind tunnel. Following reading and discussion of Robert Venturi's "difficult whole" and the mash-up, students combined six of these readymades within a 50' cube based on a comfort narrative shaped by their climatic, formal, spatial and material aspects. They then documented this work in three dimensional models and collages (figure 2 ).

This exercise led into the design of the athletic club, which was to be organized around different indoor climates to support multiple and changing programs, rather than dimensionally-fixed programmatic areas. The model for this organization was the Köppen Climate Classification, a widely used empirical system that defines global climates as they correspond to different vegetation zones. For the athletic club, I established seven potential indoor climates, with different WB and DB temperatures, wind speeds etc., as they correspond to different experiences. These included parameters for a hot, humid space, an arid space, a chilled space and a cold space as well as the standard ASHRAE indoor climate and unconditioned outdoor spaces.

To organize these climates, students constructed comfort narratives that addressed one or more of the following ideas: thermal onions, materials as heat sinks and heat sources, indoor weather and the architectural sublime. Thermal onions are spatially nested thermal conditions that can directly connect spatial organization with comfort. Materials can act as heat sinks and heat sources, just like the more common and less efficient medium of air, while also providing structural support and spatial enclosure. Indoor weather systems are the result of the redistribution of energy around the building just as outdoor weather is the result of the redistribution of energy around the globe. The architectural sublime combines awe and pleasure to give discomfort a stimulating potency that contrasts sharply with the banality of most building comfort.

I evaluated students' final projects on their ability to connect different interior environments to compelling building forms, spaces and materials. This approach removed the design of environmental systems from building's technological systems to focus instead on the qualitative aspects of the architectural environment, and on developing an architectural narrative for this environment. One group abstracted different material and spatial conditions of vernacular forms, and combined them to create a microcosm of global climates (figure 3). Another organized their proposal based on indoor weather systems that were in dialogue with the changing outdoor seasons (figure 4). The outcome of this studio was to recognize the potential of architectural climates to substantially inform architectural design. Rather than passively accepting homogeneity of most interior climates, students engaged with the design of the building interior as a material and energetic whole. Students designed building envelopes as a symbolic and performative interface 
between artificial and natural climates. Interior spaces were given a narrative structure that engaged the experiences of being in the building, rather than just its geometric composition.

I am currently extending this approach from an options to a core junior studio. One of the studio's thee themes is environmental entanglement, which holds that by manipulating form, architecture creates environments, while also creating connections between the artificial world of buildings and the natural world of ecosystems. Adding this pedagogical focus is challenging. Implementing such changes involves educating both fellow faculty and students. Some faculty reflexively view such issues through the lens of sustainability, which to them is separate from design. Having a core cohort of committed faculty would likely help in meeting this challenge. While students often work with manipulating light through their design work, other environmental qualities like temperature, air and sound are less familiar. Their non-visual nature makes them more difficult for students to incorporate into their standard workflows which rely almost exclusively on how something looks rather than the environments it creates. Students and critics need to discuss and represent these phenomena during the design process, and in the final project documentation.

\section{IV.}

The final example is a building systems class with the cumbersome name "Environmental, Mechanical \& Electrical Systems in Architecture 2." This is a required class for graduate students that fulfils a number of the NAAB Student Performance Criteria. When I took over this class four years ago, it had been taught for over a decade by a local engineer/architect, with whom I was to share teaching responsibilities. The two directions I was given were to make the material more relevant to the students' studio work, and to maintain the school's high pass rate on the building systems portion of the ARE.

The class had been organized using a conventional sequence that followed the nearly 2000 page Mechanical and Electrical Equipment for Buildings (2015) textbook. I reorganized the class into three sections focused on three different environments and the experiences they create: the thermal environment, the luminous environment and the acoustic environment. The structure of each section follows a similar pattern. We first review basic physics and then discuss how these concepts play out in buildings. In the thermal environment section, we review the basics of climate, heat flow and psychometrics, after which we apply them to building siting, envelope design, typical mechanical distribution and more innovative approaches to mechanical conditioning. In the luminous environment section, we review the principles of electricity and light before presenting basic natural and artificial lighting strategies and calculations. In the acoustic environment section, we present the basics of sound and how material assemblies interact with different sound frequencies and levels.
Each week, my co-teacher and I alternate lectures. We each have a different approach to the material, and to the student learning outcomes we expect. His approach is quantitative, focusing on basic calculations (heat gain, lumen and decibel levels), while mine is qualitative, focusing on vocabulary to introduce students to terms describing the architectural environment. Calculations demystify opaque design processes, while vocabulary allows students to participate in conversations with other building professionals. For his lectures, he draws examples from a forty-year long career working on commercial and civic buildings that are generally fall within standard practice. For my lectures, I discuss historical and contemporary buildings, many of them familiar to students from other classes, that focus on atypical, innovative solutions.

There is a productive dissonance in our different approaches to the same material. Making a building is a highly context dependent process, both the ecological context which the building participates in as well as the cultural and economic context which outline the possibilities of its creation. To strategically change a situation, it is important to understand how things are typically done and then consciously shift understanding in a new direction. The idea is to create a "choice architecture" for the architectural environment. Rather than the default solutions (sealed building envelope, separate indoor and outdoor climates, an exclusive focus on equipment efficiency for energy savings) the way information is presented nudges students towards making better, more engaged, design decisions. ${ }^{7}$ This is certainly a tall order for an ancillary class that has significant responsibility in fulfilling $\mathrm{NAAB}$ accreditation requirements. But it reflects an approach that, if found elsewhere in an architectural curriculum, can reinforce a broader messages about architectural comfort. Perhaps over time this will be reflected in larger social systems that govern the profession, such as the ARE.

V.

In his history of architecture's primitive huts, Joseph Rykwert concludes "The return to origins always implies a rethinking of what you do customarily, an attempt to renew the validity of your everyday actions." ${ }^{8}$ Explicitly addressing the construction of comfort, both buildings' physical construction and the social construction that defines our expectations of them, we similarly rethink normative understanding of architecture as part of larger ecological processes. As an early example of such conscious attention to comfort, Robinson Crusoe captivated the western imagination. Its popularity spawned a literary genre called Robinsonades, desert island dramas and castaway narratives whose storylines shared common themes involving the status of nature, the progress of technology and social commentary formed by an isolated individual or small group. These ranged from the utopian Swiss Family Robinson (1812) to the dystopian Lord of the Flies (1954). The genre continued in 1960s science fiction and can be found in climate fiction of recent decades. 


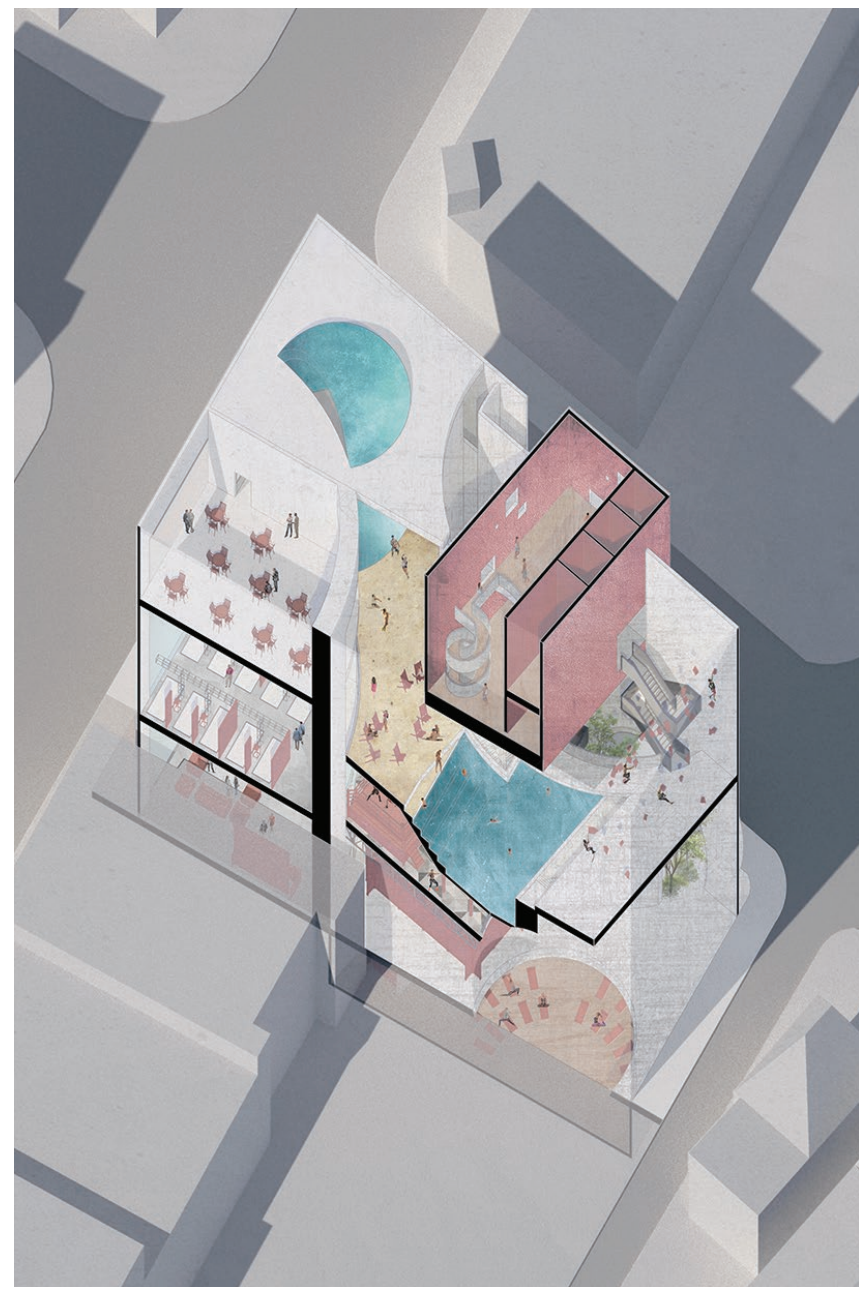

Figure 3. New Columbus Athletic Club, Yutong Lu and Tian Wang.

The three classes presented here are explorations of how architectural pedagogy can be shaped by explicit attention to comfort. They present comfort as an understudied part of architecture's environmental history, and a vital direction for its future as part of an expansive ecological vision. The seminar shows how a cultural understanding of comfort can bridge the gap between architecture's expectation of design innovation with rules-based knowledge associated with technology. The studio has students link different architectural climates with different architectural forms, thus connecting comfort with design. Through the productive dissonance of the shared lectures, the systems class shows students that building equipment represents design choices with implications far beyond the mechanical room. Collectively, my goal for these is to make students and faculty alike uncomfortable with dominant attitudes toward comfort, and to embrace architecture's ecological entanglements as rich sources of creative and cultural engagement.

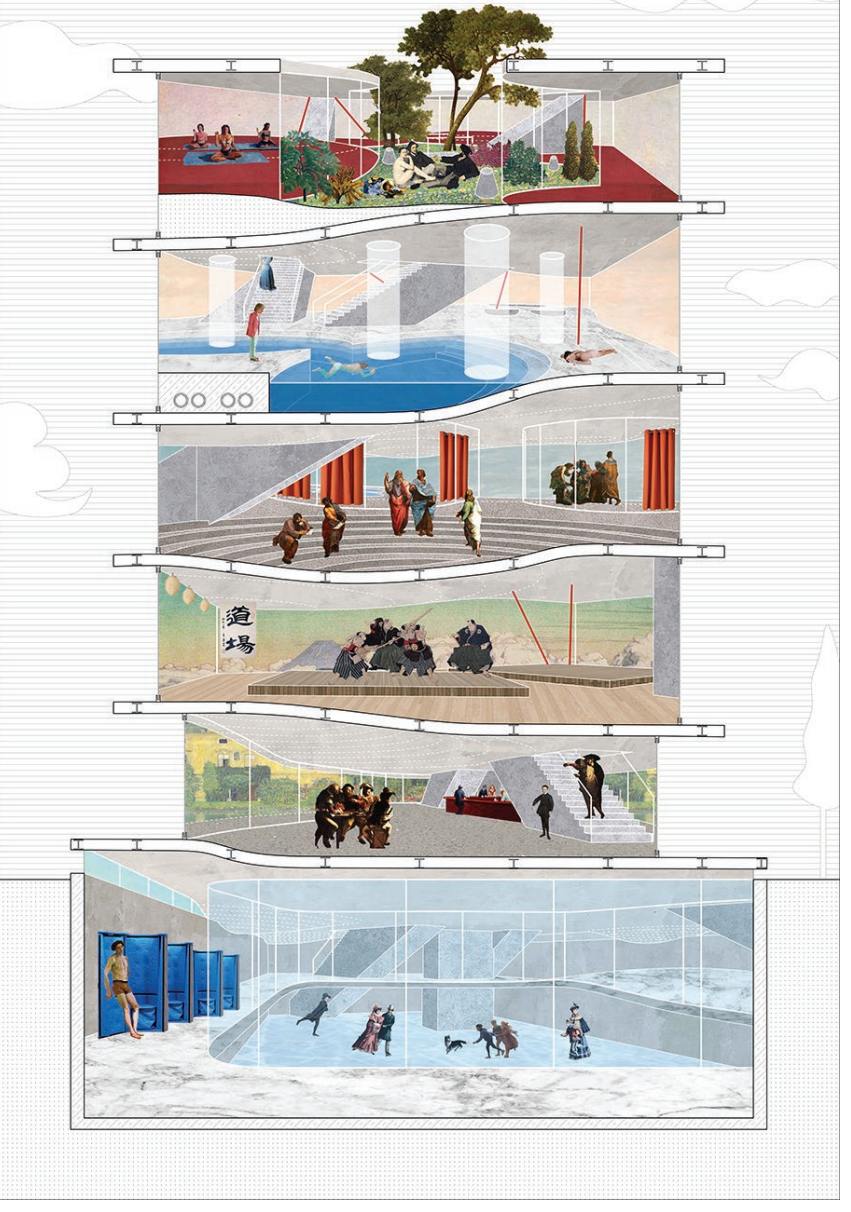

Figure 4. New Columbus Athletic Club, Guanming Huang and Zhengda Liu.

\section{ENDNOTES}

1 Joseph Rykwert, On Adam's House in Paradise: The Idea of the Primitive Hut in Architectural History (Cambridge, MA: The MIT Press, 1981), 13.

2 Daniel Defoe, Robinson Crusoe (The Life and Strange Surprising Adventures of Robinson Crusoe of York, Mariner) (New York: Oxford University Press, 2007).

3 John E. Crowley, The Invention of Comfort: Sensibilities \& Design in Early Modern Britain \& Early America (Baltimore: Johns Hopkins University Press, 2001).

4 Norbert Elias, The Civilizing Process (New York: Urizen Books, 1978).

5 P.O. Fanger, Thermal Comfort: Analysis and Applications in Environmental Engineering (New York: McGraw-Hill Book Company, 1972), 85-95.

6 The bibliography of comfort is drawn from diverse sources. Among the stronger examples are French historian Alain Corbin, whose writing focuses on the history of sensibilities such of sounds and smells. In The Lure of the Sea: The Discovery of the Seaside, trans., Jocelyn Phelps (New York: Penguin Books, 1994) he addresses the sublime comfort of sea bathing. English sociologist Elizabeth Shove illustrates the social construction of energy consumption through thermal comfort in Comfort, Cleanliness and Convenience: The Social Organization of Normality (New York: Berg, 2003). Considering comfort as a cultural construct, anthropologists Peter Richardson and Robert Boyd study the nimble role of cultural evolution as a counterpoint to slower process of biological evolution in Not by Genes Alone: How Culture Transformed Human Evolution (Chicago: University of Chicago Press, 2006). Evolutionary biologist Daniel Lieberman reviews the hid den dangers and novelty of comfort in The Story of the Human Body (New York: Penguin, 2013). Architectural historians Jiat-Hwee Chang and Tim Winter begin a nuanced understanding of the air-conditioned comfort in "Thermal Modernity and Architecture," The Journal of Architecture 20, no. 1 (2015): 92-121.

7 Richard H. Thaler and Cass R. Sunstein, Nudge: Improving Decisions About Health, Wealth, and Happiness (New York: Penguin Books, 2008).

8 Rykwert, On Adam's House in Paradise, 192 